\title{
Narrative review of multiparametric ultrasound in parotid gland evaluation
}

\author{
Milvia Martino ${ }^{1}$, Daniela Fodor ${ }^{2}$, Daniele Fresilli ${ }^{3}$, Olga Guiban ${ }^{3}$, Antonello Rubini ${ }^{4}$, Andrea Cassoni ${ }^{5}$, \\ Massimo Ralli ${ }^{6}$, Chiara De Vincentiis ${ }^{7}$, Federico Arduini ${ }^{8}$, Ilaria Celletti ${ }^{3}$, Patrizia Pacini ${ }^{3}$, Giorgia Polti ${ }^{3}$, \\ Eleonora Polito ${ }^{3}$, Antonio Greco ${ }^{6}$, Valentino Valentini ${ }^{5}$, Salvatore Sorrenti' ${ }^{9}$, Vito D'Andrea ${ }^{10}$, \\ Carlo Masciocchi ${ }^{1}$, Antonio Barile ${ }^{1}$, Vito Cantisani ${ }^{3}$
}

${ }^{1}$ Department of Biotechnological and Applied Clinical Sciences, University of L'Aquila, L'Aquila, Italy; ${ }^{2} 2$ nd Internal Medicine Department, "Iuliu Hațieganu” University of Medicine and Pharmacy, Cluj-Napoca, Romania; ${ }^{3}$ Department of Radiological Sciences, Oncology and Pathology, Policlinico Umberto I "Sapienza” University of Rome, Rome, Italy; ${ }^{4}$ Department of Radiology, Rome, Italy; ${ }^{5}$ Department of Maxillofacial Surgery, Policlinico Umberto I "Sapienza” University of Rome, Rome, Italy; ${ }^{6}$ Department of Sense Organs, Sapienza University of Rome, Rome, Italy; ${ }^{7}$ Department of Radiology, Ospedale Sandro Pertini, Rome, Iataly; ${ }^{8}$ Department of Radiology, Ospedale Santa Maria del Carmine, Rovereto, Italy; ${ }^{9}$ Department of Surgical Sciences, “Sapienza” University of Rome, Rome, Italy; ${ }^{10}$ Department of Surgical Sciences, "Sapienza” University of Rome, Rome, Italy

Contributions: (I) Conception and design: V Cantisani, M Martino; (II) Administrative support: D Fresilli, O Guiban, G Polti, E Polito, P Pacini, V D'Andrea; (III) Provision of study materials or patients: D Fodor, V Cantisani, S Salvatore; (IV) Collection and assembly of data: A Rubini, D Fresilli, O Guiban, G Polti, E Polito, P Pacini, I Celletti, A Cassoni, M Ralli, C De Vincentiis, F Arduini; (V) Data analysis and interpretation: M Martino, V Cantisani; (VI) Manuscript writing: All authors; (VII) Final approval of manuscript: All authors.

Correspondence to: Milvia Martino. Department of Biotechnological and Applied Clinical Sciences, University of L'Aquila, 67100, L'Aquila, Italy. Email: aivlim@hotmail.it.

\begin{abstract}
Disorders affecting parotid gland represent a heterogeneous group comprising congenital, inflammatory and neoplastic diseases which show a focal or diffuse pattern of appearance. The differentiation of neoplastic from non-neoplastic conditions of parotid glands is pivotal for the diagnostic imaging. Frequently there is evidence of overlapping between the clinical and the imaging appearance of the various pathologies. The parotid gland is also often object of study with the combination of different techniques [ultrasound-computed tomography-magnetic resonance imaging (US-CT-MRI), ex.]. Compared to other dominant methods of medical imaging, US has several advantages providing images in real-time at lower cost, and without harmful use of ionizing radiation and of contrast enhancement. B-mode US, and the microvascular pattern color Doppler are usually used as first step evaluation of parotid lesions. Elastography and contrast-enhanced US (CEUS) has opened further possible perspectives to improve the differentiation between benign and malignant parotid lesions. The characterization of the parotid tumors plays a crucial role for their treatment planning and for the prediction of possible surgical complications. We present, here an updated review of the most recurrent pathologies of parotid gland focusing on the diagnostic power of multiparametric US including CEUS and ultrasound elastography (USE); limitations, advantages and the main key-points will be presented
\end{abstract}

Keywords: Elastography; contrast-enhanced ultrasound (CEUS); parotid gland; multiparametric ultrasound (multiparametric US); parotid lesions

Submitted May 27, 2020. Accepted for publication Oct 12, 2020.

doi: $10.21037 / g s-20-530$

View this article at: http://dx.doi.org/10.21037/gs-20-530 


\section{Introduction}

Ultrasound (US) is nowadays considered an efficient imaging technique for the diagnosis, follow-up and therapeutic procedures of different pathologies in several organs (1-5), especially thanking to the introduction of innovative techniques $(6,7)$.

US is often considered the first line screening imaging modality and, depending on its findings, may determine the necessity for the next best diagnostic step, including computed tomography (CT), magnetic resonance imaging (MRI) and other techniques (8-15). The utility of US for interventional procedure guidance such as for tissue sampling and biopsy, interventional drainage procedure or surgical excision is well recognized (16-20).

Among the different organs assessed properly by US, parotid glands have been evaluated successfully in the last 20 years as the glands are easily accessible and the technique is highly accepted by the patients due to its safety profile.

Disorders affecting parotid gland represent a heterogeneous group comprising congenital, inflammatory and neoplastic diseases with focal or diffuse pattern of appearance. Although highly sensitive, grey-scale US (GSUS) has not enough specificity to distinguish the different imaging patterns of parotid pathologies. As a consequence, different authors suggested a multiparametric US (MPUS) approach of salivary glands (21-24), including the innovative techniques for obtaining a correct prognostic, diagnostic and therapeutic strategy. The main aim of using proper imaging modality is to avoid high risks related to therapeutic decisions. Different surgical procedures (e.g., extracapsular dissection and partial, superficial, total, or radical parotidectomy) can be adapted based on the preoperative knowledge to ensure radicality, the preservation of functional structures as facial nerve and to reduce patient's morbidity (25). A multimodal US pathway includes, besides clinical and laboratory data, the use of GSUS, color-Doppler (CD) US (CDUS), US-elastography and contrast-enhanced US (CEUS) (26-30).

In the present paper we report an updated overall representation of MPUS evaluation of a wide panoply of focal and diffuse salivary glands pathology. We present the following article in accordance with the NARRATIVE REVIEW reporting checklist (available at http://dx.doi. org/10.21037/gs-20-530).

\section{US techniques}

\section{GSUS}

The examination is performed using the highest frequency transducer possible while $5-10-\mathrm{MHz}$ transducers may be useful to evaluate the deep portions of the glands. The technique was published and the normal aspect of parotid gland was defined (31-34). A systematic approach is needed in order to provide a complete assessment. It consists in the evaluation of all the structural components of both salivary glands (parenchyma, vessels, ducts, lymph nodes etc.) using US criteria such as volume, margins, echotexture, echogenicity, etc. Variable appearance can be found in healthy population; Badarinza et al. recently published an atlas with 4 scale grades of parotid echogenicity and found that $12 \%$ of healthy non-obese people had inhomogeneous parenchyma (30).

In case of parotid lesions detections, several parameters should be reported: the largest dimension on the axial and longitudinal planes; margin definition; echotexture (homogeneous or heterogeneous appearance); the presence of internal contents (solid or cystic); regional lymph node including size, morphology and the presence of hilar fat; presence of acoustic enhancement of the lesion, etc. (35).

In addition to the traditional and high-resolution US evaluation (36-38), recently quantitative evaluation of parotid gland echogenicity by means of grey-scale histogram measurements (ROI) was also reported. The gland histogram ratio (mean grey-scale histogram parotid/ mean grey-scale histogram subcutaneous fat) on healthy subjects and patients with parotid abnormalities can be also determined (39-41).

US is used also to guide fine-needle aspiration biopsy (FNAB) or core-biopsy, procedures that represents the "gold standard" in the preoperative evaluation of focal parotid lesions $(35,42,43)$.

\section{CDUS and superb microvascular imaging (SMI)}

All Doppler US techniques can be used in salivary glands pathology. Using color Doppler, the speed and direction of moving blood cells can be determined, while power Doppler US provides high sensitivity in detection the slow flow (44). High vascularization is generally associated with the suspicion of malignancy and low vascularization may be considered a sign of benign behaviour (45). Recently, new techniques such as SMI were introduced (46-49). SMI is a new Doppler technique that is able to reveal thinner vascular structures avoiding motion artefacts. Recent studies 
have been published using the SMI technique for liver, kidney, testis and parotid in pediatric population (50-53).

\section{CEUS}

CEUS, an US technique based on administration of contrast providing blood flow measurement as a reflection of neo-angiogenesis in response to tumor or inflammation, adds precisely information about the micro-vascularization. The usefulness of CEUS is well documented in liver and non-liver applications (54-61).

CEUS is easily performed and contrast injections may be repeated, due to the strong safety profile of microbubbles with a low risk of adverse events and no renal excretion (62).

Depending on the CEUS aspect, Wei et al. (63) described three patterns for focal parotid lesions types: type 1-diffuse homogeneous enhancement; type 2heterogeneous enhancement; and type 3-no enhancement or iso-enhancement. Types 1 and 3 are suggestive of benign tumours and type 2 can indicate the presence of a malignant lesion.

In addition, CEUS can provide quantitative specific measurements of the contrast dynamic performance due to contrast agent that can be monitored over time with enhancement behaving in a uniform manner. Time intensity curve analyses include the time to initial peak (TP), signal intensity (SI max), the area under time intensity curve (AUC) and mean transit time (MTT) (64).

Klotz et al. (65) highlighted the role of the specific parameters quantified from CEUS measurements. The AUC and MTT showed a statistically significant higher value for malignant lesions. Differences in AUC, peak enhancement (PE), wash-in rate (WiR) and wash-in perfusion index (WiPI) in malignant compared to benign tumours and in pleomorphic adenoma (PA) compared to Warthin's tumour (WT) were demonstrated.

\section{US elastography}

US elastography US techniques, according to the recent guidelines (66-69), recognize different approaches.

Strain elastography (SE) is based on the measurement of the shape deformation of a tissue in a region of interest as expression of the tissue elasticity providing qualitative or semi-quantitative information. Klintworth et al. (70) described few elastographic patterns of parotid tumors using SE. The benign lesions had more frequently the "bull's eye sign" a very soft, ellipsoid area in the centre of a lesion (parotid cysts), "dense core sign" very stiff tissue in the core and a softer tissue in the adjacent zone (PAs), "half- half sign", with a stiff superficial area and a deeper softer area (WTs). Malignant parotid lesions are associated to the "garland sign". The authors realized a scoring system based on the analysis of specific elastographic patterns in different parotid pathologies.

Shear wave speed (SWS) measurement includes transient elastography (TE) and acoustic radiation force impulse (ARFI) quantification, as a point shear wave elastography (p-SWE) or, if applied to a larger field of view, as bidimensional (2D) SWE. The transducer induces high acoustic pulse with a displacement of the tissue measuring the speed of the generated shear wave. SWE is a technique independent to an external source for stress generation so it is more reproducible than SE, providing quantitative stiffness information. Both techniques can be used in different clinical applications (71-74) and in parotid pathology characterization. (75)

Normal stiffness values for the parotid gland in pediatric (76) and adult population (30) were published; in particular, Zengel et al. (77) reported that ARFI provides a quick, easy and reliable diagnostic tool for the assessment of disease severity.

\section{Other advanced imaging methods}

\section{CT}

CT imaging provides valid contribute in the staging due to the power to detect local extension and the spread of cervical lymph nodes and for the good evaluation of the involvement of soft tissue, bone and perineural structures when there is a large infiltration of the nerve (78). CT is also useful in the classification of parotid gland lesions into benign and malignant tumors but the results were often inconsistent. CT's sensitivity and specificity are low in the post-treatment surveillance (79) and the major limit is represented by the radiation exposure (80-83)

Dual-energy CT may be a useful modality for tumoral analysis $(78,84-86)$.

Positron emission tomography (PET)-CT is unrivaled for distant metastases but it is not reliable in distinguishing benign from malignant tissue. WTs can also be FDG avid as many malignant lesions. Conversely, some malignant tumors, such as adenoid cystic carcinoma, have variable or low uptake of FDG (79).

CT perfusion has a potential to differentiate benign and malignant tumors by demonstrating higher blood flow and volume in benign neoplasms, but the radiation exposure, which is higher than in conventional CT (79). 


\section{MRI}

MRI including diffusion weighted imaging (DWI)apparent diffusion coefficient (ADC)-dynamic contrast enhanced (DCE), has been widely applied for preoperative diagnosis of parotid gland lesions to monitor the post-treatment response, and to differentiate recurrent tumor from post-treatment changes. The potential role of MRI is based on the detection and characterization of malignancies extension, evaluation of perineural tumor spread CN VII facial, assessment for osseous marrow involvement. However, MRI is imperfect for a definitive diagnosis. ADC also could provide a high accuracy for identifying parotid gland lesions. Many studies look at the hypointense signal on ADC as a marker. According to previous reports, ADCs of parotid gland carcinomas (malignant) were statistically lower than those of PAs (benign), but higher than WTs (benign) DCE. Malignant neoplasms demonstrate rapid enhancement, but washout tends to be relatively slower than in WTs (78,79,87-90). The first limit of MRI is represented by the administration of the contrast-enhancement (91-93).

\section{Methods}

An online literature search on PubMed and MEDLINE was exploited to identify articles in English investigating on US and diagnostic evaluation of parotid gland diseases up until April 2020. Keywords queried included a various arrangement of the following terms: "ultrasound", "US", "CT", "MRI", "parotid gland", "parotid gland neoplasia", "Parotid gland inflammations". Eligibility criteria excluded articles that reported parotid gland pathology not written in English. Additional queries were performed based on relevant references of the searched articles as well.

\section{Parotid gland pathologies}

The age and clinical patient information represent a helpful tool for the diagnosis because vascular and congenital lesions appear in the first years of life, inflammation diseases have a rapid appearance and evolution than solid tumors which are more gradual and usually are more frequent in the older age. An overview of the most common pathologies of the parotid gland is reported below taking into account what described in literature.

\section{Parotid gland lesions}

\section{Focal lesions}

\section{Benign tumors}

Parotid benign tumors affect parotid gland in about $80 \%$ of cases, localizing frequently in the superficial lobe of the gland. The most frequent benign tumor of the parotid gland in adults is PA (94) and in children hemangiomas. Tumors like WT, adenoma, papillary cyst adenoma, oncocytoma, lipoma, neurofibroma (solitary or plexiform types), hamartoma and lymphoepithelial tumors occur rarely (36).

(I) PA

* US: well defined, lobular shaped lesion. Typically, they appear as homogeneous hypoechoic lesion but sometimes, long-standing lesions may appear inhomogeneous due to internal cystic degeneration or dystrophic calcification appearing. Acoustic enhancement frequently is present (95) (Figure 1).

* CDUS-SMI: poorly or mainly peripherally vascularized but no central flow; very rarely depending on the size they may show increased vascularization (Figure 2).

* CEUS: poorly vascularized lesion; contrast enhancement is visible only in the peripheral wall and within internal septa $(45,95)$.

* SE: elevated strain ratio suggesting medium/high stiffness of the lesion. In particular, SE reliably distinguishes cystic lesions and PAs when they show overlapping features $(95,96)$.

\section{(II) WT}

* US: Parotid tail region. Rounded or lobulated hypoechoic masses and regular margins that may show cystic areas with hyperechoic internal septation. In general, no acoustic enhancement is present (45).

* CDUS-SMI: rich peri- and intra-lesional vascularization.

* CEUS: diffuse and homogeneous contrast enhancement. Time/intensity curves confirm intense vascularization of the lesion.

- SE: low value of strain ratio suggestive of benign disease.

SWE: soft elastographic pattern $(95,96)$.

\section{(III) Oncocytoma}

* US: well-circumscribed, lobulated, ovoid shape and hypoechoic aspect (97). 

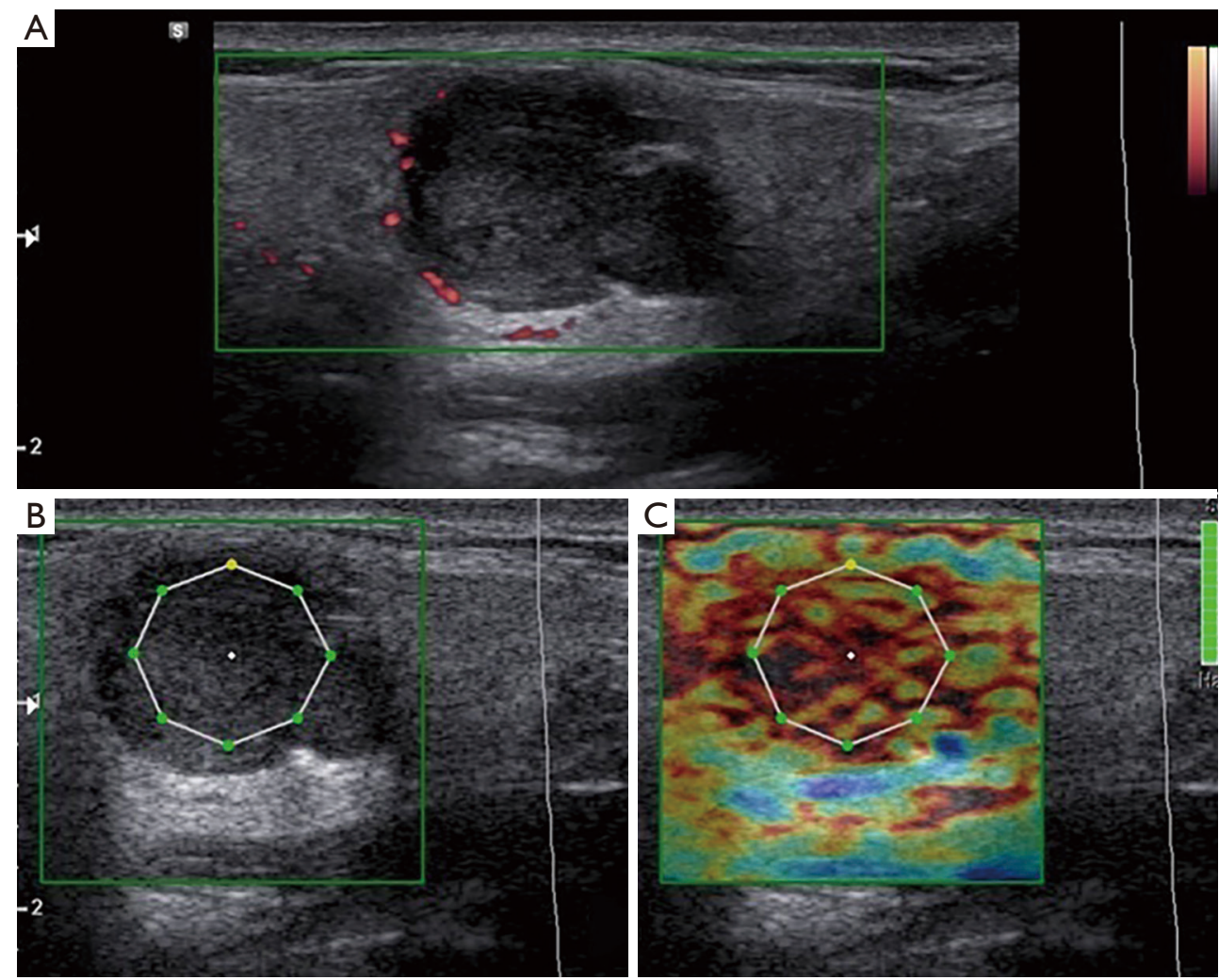

Figure 1 Grey scale, color Doppler (A) and elastography (B,C) aspect in a patient with pleomorphic adenoma. (A) Iso/hypoechoic lesion of the parotid gland with polycyclic margins, acoustic posterior enhancement and poor peripheral vascular spots but no central flow at colorDoppler US. (B,C) Semiquantitative strain elastography evaluation showed a medium/high stiffness. At the Shear wave elastography the colorimetric pattern of the lesion appears "hard". The lesion presented high value of ECI at elastography evaluation. It was a pleomorphic adenoma. ECI, elasticity contrast index.
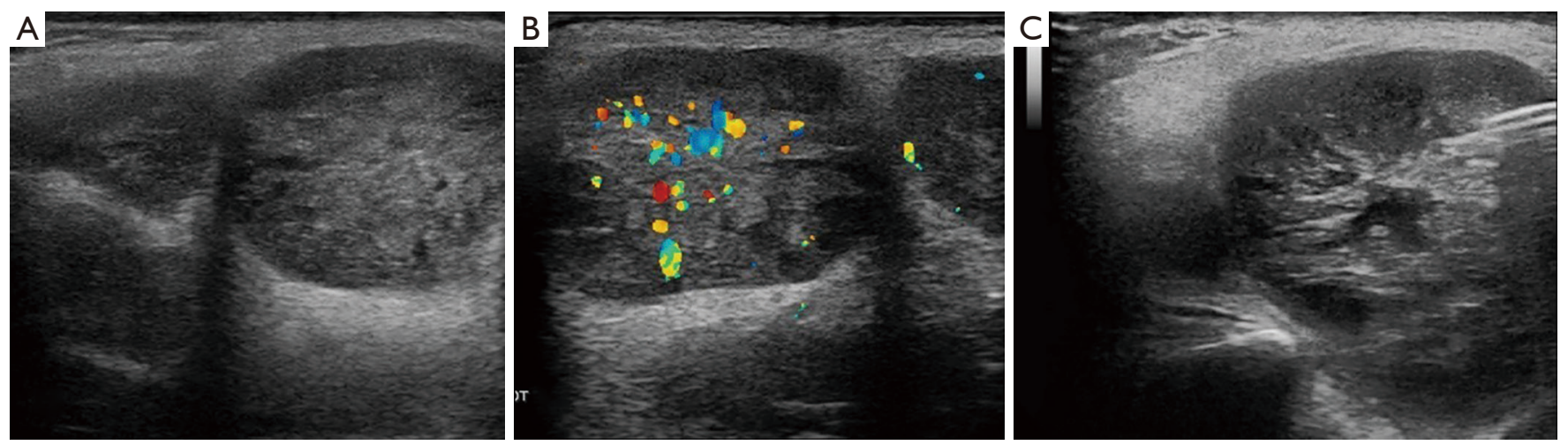

Figure 2 Longstanding pleomorphic adenoma with inhomogenous structure (A) and hypervascularization (B), biopsied under ultrasonographic guidance $(\mathrm{C})$. 
* CD-SMI: diffuse peripheral vascularization with some central vessels.

* CEUS: intense vascularization, higher than the surrounding parenchyma, confirmed by time/ intensity curves.

* SE: low strain ratio value.

* SWE: primarily soft with low stiffness (95).

(IV) Hemangioma

* US: iso-hypoechoic, compressible nodular lesion with mixed echo-structure. Sometimes it may present phleboliths within the lesion $(95,98,99)$.

* CDUS-SMI: centripetal globular vascularization (36).

* CEUS: peripheral globular progressive enhancement.

* Elastography: in general, may show softintermediate appearance but the appearance may change according to the size and the homogeneity of the lesion.

\section{(V) Lipomas}

* US: well-defined but rarely may also be ill-defined. Isoechoic to adipose soft tissue or hypoechoic with internal hyperechogenic foci or striations (95).

* CDUS-SMI: no evident vascularization.

* CEUS: no enhancement is generally reported.

* Elastography: in general, at elastography the lesion appears soft.

\section{Malignant tumors}

The overall incidence of parotid malignancies is the $3 \%$ of the head and neck region neoplasms (94). In children and adults, mucoepidermoid carcinoma followed by acinic cell carcinoma are the more frequent malignant parotid glands neoplasms. Other relatively rare tumors include adenocarcinomas, cystic adenoid carcinomas, squamous carcinomas, rhabdomyosarcomas and primary lymphoma (36).

Malignancy is generally associated to heterogeneous echotexture appearance with microcalcifications, indistinct margins, regional lymph node enlargement, and absence of distal acoustic enhancement. Significant difference is represented by the presence of regional lymph node enlargement (35).

\section{(I) Mucoepidermoid carcinoma}

* US: lower grade tumors appear well-defined with smooth border and homogeneous structure. High-grade aggressive lesions show hypoechoic inhomogeneous internal architecture, with illdefined margins and signs of surrounding structures infiltration. Cystic components can be predominant. Pathologic lymph nodes enlargement $(100,101)$
(Figure 3).

* CD-CEUS: highly and irregularly vascularized.

* Elastography: the lesion appears mostly hard (95).

\section{(II) Lymphoma}

The appearance is highly variable, manifesting as focal or diffuse, single or multiple, and unilateral or bilateral masses which may appear hypo echoic, cystic or microcystic.

* US: primary lymphomas of the salivary glands are often infiltrative with diffuse gland enlargement and, eventually, irregularly vascularized. Secondary lymphomas can have the same appearance or present as enlarged lymph nodes in the parotid glands, sometimes with pseudo-cystic or micronodular pattern (78).

* CD-SMI and CEUS: they may be highly vascularized or in the colliquative cases hypovascularized.

* Elastography: depending on the differentiation grade it may appear hard or soft.

\section{(III) Metastasis}

Common skin malignancies which metastasize to the parotid lymph nodes include squamous cell carcinomas and melanomas, followed by other tumors involving kidney, breast, and lung (78). These typically manifest with lymph node enlargement within the parotid gland.

* US: hypoechoic with heterogeneous internal architecture and ill-defined margins. Enlarged intra-parotid lymph nodes or lymph nodes that are growing over time are a suspicious finding $(95,102)$.

* CD-CEUS-elastography: the appearance of Metastasis is very variable it depends on the diagnostic features of the primary tumor.

\section{Inflammatory conditions}

Acute and chronic inflammatory conditions can be caused by infections or different processes: autoimmune, systemic and neoplastic.

\section{Acute parotitis}

Acute parotitis is the most common parotid inflammatory condition in pediatric population. US is the reference standard for the diagnosis of acute parotitis.

\section{Viral parotitis}

* US: in $75 \%$ of cases both parotid glands are enlarged with a more rounded shape. Heterogeneous and relatively hypoechoic structure. Sometimes the salivary ducts are enlarged without calculi. Cervical 

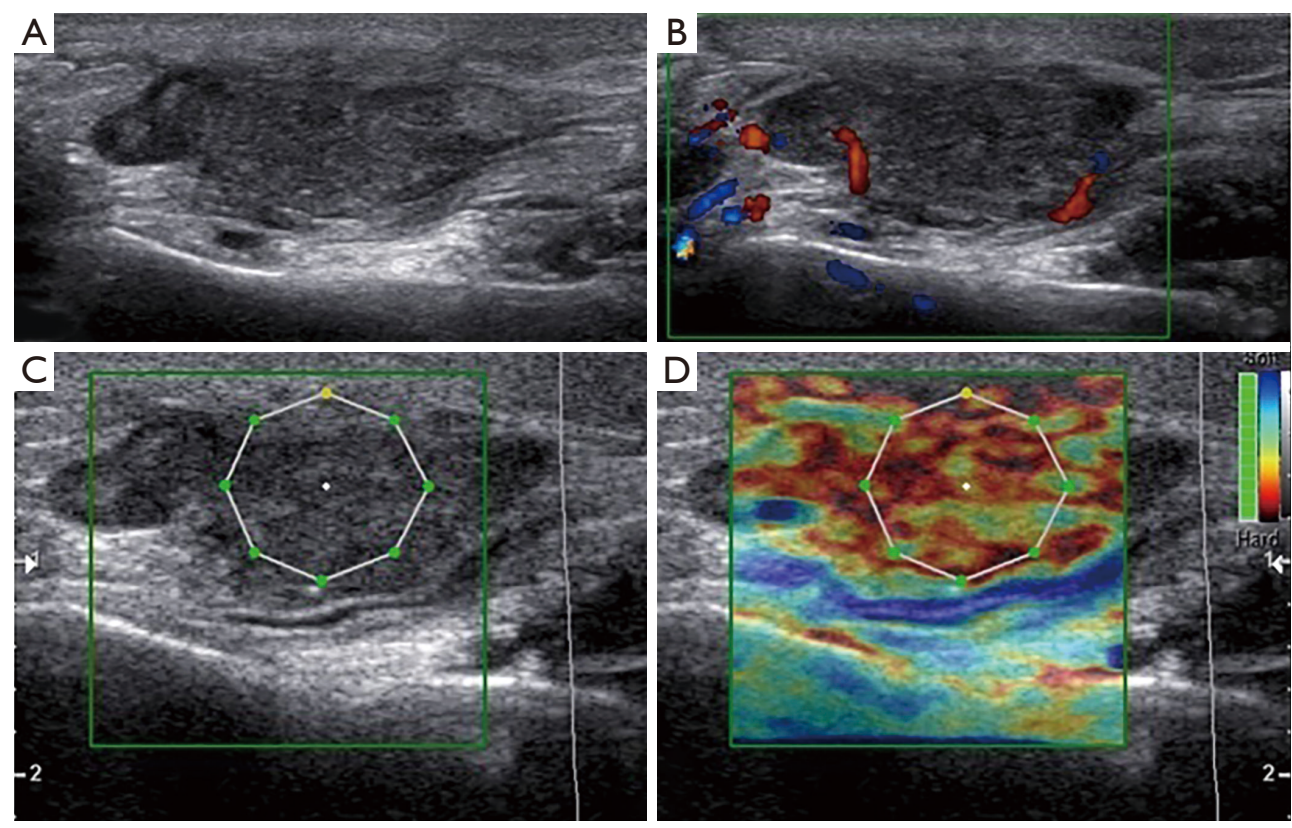

Figure 3 Grey scale (A), color Doppler (B) and elastography (C) aspect in a patient with a mucoepidermoid carcinoma of the parotid gland. (A) High-grade aggressive lesions showing an irregular structure with hypoechoic inhomogeneous internal architecture, polycyclic margins and posterior acoustic enhancement; (B) at color-Doppler US the lesion showed internal vascular signs and some spots in the peripheral region; (C) the lesion showed high value of ECI at elastography evaluation. The nodule is red on the color map, indicating a "hard" lesion. It was a mucoepidermoid carcinoma of the parotid gland. ECI, elasticity contrast index.

lymph nodes are also always enlarged (Figure 4).

* CD: they appear diffusely hypervascularized $(36,100,101)$.

\section{Bacterial parotitis}

Acute bacterial parotitis is as common in adults as in children. Sialadenitis in adults is associated in approximately $50 \%$ of cases with sialolithiasis (100).

* US: typically, unilateral. Enlargement of the gland with poorly defined margins and heterogeneous echostructure characterized by foci of lymph nodes or a mixture of exudate and saliva determining the obstruction of the gland alveoli and a subsequent salivary ducts dilatation. It can be seen anechoic or hypoechoic areas of suppuration (pus) implying abscess formation.

* CD: gland increased vascularization $(101,103,104)$.

\section{Recurrent parotitis (RP)}

In children is a relatively common disease:

* US: in acute phases, enlarged heterogeneous gland, with round, hypoechoic and anechoic regions of 2-4 $\mathrm{mm}$, which may correspond to the ectasia of the ducts or lymphocytic infiltration are visible (36). In the adult form of RP, the gland appears atrophic and hypoechoic with stenoses and dilatations mainly formed along Stensen's canal creating "string of pearls" image. Parenchyma can become fibrotic (100).

- CD: hypervascularization of the intra- and extraglandular tissues.

* Elastography: lower tissue elasticity compared to healthy glands manly depicted in patients with symptoms for more than a year. ARFI shear wave velocity (SWV) is a promising diagnostic tool for in the initial examination and follow-up therapy of patients with RP, especially in cases with fibrosis development (77).

\section{Sialolithiasis}

It is now generally acknowledged that lithiasis formation can be found during early childhood but it is most common 

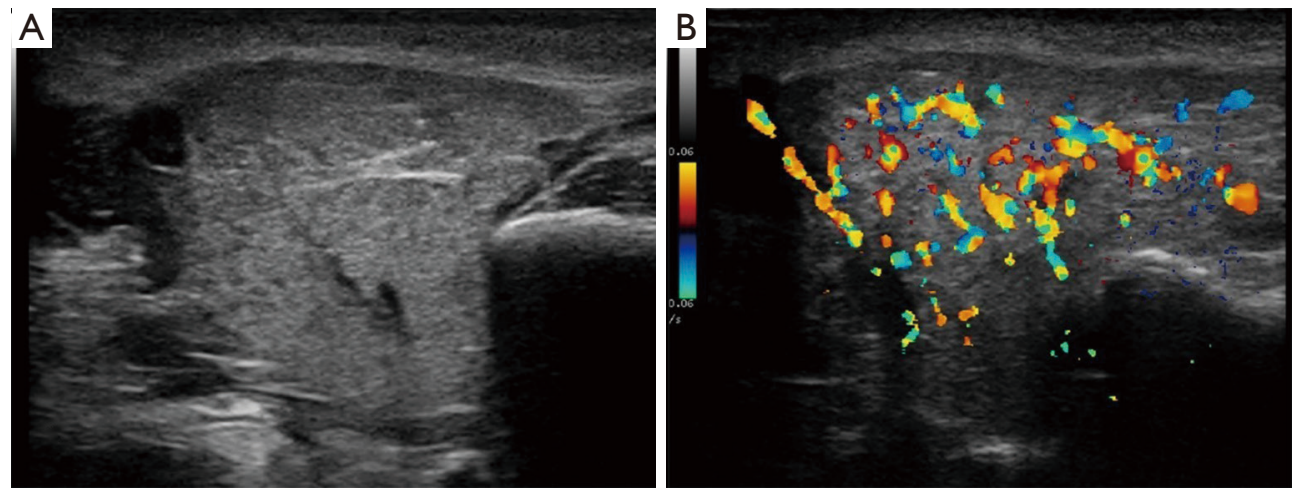

Figure 4 Grey scale (A) and color Doppler (B) aspect in acute viral parotitis. The gland is enlarged, diffuse inhomogeneous and hypervascularized.

in adult age.

* US: uni- or bilateral. The presence of one or more calculi is revealed as bright curvilinear echo complex with acoustic shadowing. Gland appears diffusely hypoechoic with globular margins. The glandular volume gradually increases with higher calculus diameters. In chronic obstructive sialadenitis, the affected parenchyma can become oedematous and fibrotic (100).

* Elastography: parotid glands with a calculus of more than $5 \mathrm{~mm}$ in diameter demonstrated a significantly reduced tissue elasticity (Figure 5). After therapy, ARFI SWV values are similar to the ones of unaffected contralateral glands. No significant differences in ARFI SWE values were detected in relation to the duration, the recurrence of episodes, the intensity of pain (105).

\section{Chronic parotitis}

\section{Sjögren's syndrome (SS)}

SS is an autoimmune, chronic systemic inflammatory disease characterized by lymphocytic infiltration of all exocrine glands. Diagnostic criteria are based on the American College of Rheumatology (ACR) and the European League Against Rheumatism (EULAR) classification criteria (106) in which no US criteria are included. Recently, US imaging has started to be a part of the classification criteria for various rheumatic diseases and it may also be a part of the classification criteria for SS in the near future.

* US: the presence of focal or diffuse anechoic/ hypoechoic foci in both parotid and submandibular glands, graded as: grade 0 , normal parenchyma; grade 1 , minimal change such as mild inhomogeneity without anechoic/hypoechoic areas; grade 2 , moderate change such as moderate inhomogeneity with focal anechoic/ hypoechoic areas; grade 3, severe change such as diffuse inhomogeneity with anechoic/hypoechoic areas occupying the entire gland surface (107).

* CD: abnormal vascularity of the parotid glands considered as an indirect sign of inflammation

* Elastography: SE demonstrated high degree of stiffness of parotid gland parenchyma (108). 2D-SWE was proven to be an effective technique for predicting interstitial fibrosis and the severity of histologic damage (109), having added value for SS diagnosis (110) (Figure 6).

\section{Tuberculosis}

Tuberculosis of the salivary glands is rare, with parotitis mimicking a malignant tumor.

* US: heterogeneous, hypoechoic, poorly-defined lesions. Large intraparenchymal nodes with relatively intact intervening parenchyma. Some of the intraparotid nodes may liquefy. The intraparenchymal calcified lymph nodes are typically seen as hypoechogenic nodules with small foci of calcification $(36,101)$.

\section{HIV}

Parotid involvement is one of the most common manifestations of pediatric HIV infection

* US: enlargement of parotid gland with nontender consistence. Multiple small areas of hypo echogenicity in the parenchyma. Sometimes HIV parotid glands involvement may show cystic appearance with slow growing masses mostly accompanied by persistent cervical or generalized lymphadenopathy.

* SWE: increased tissue stiffness when compared with 

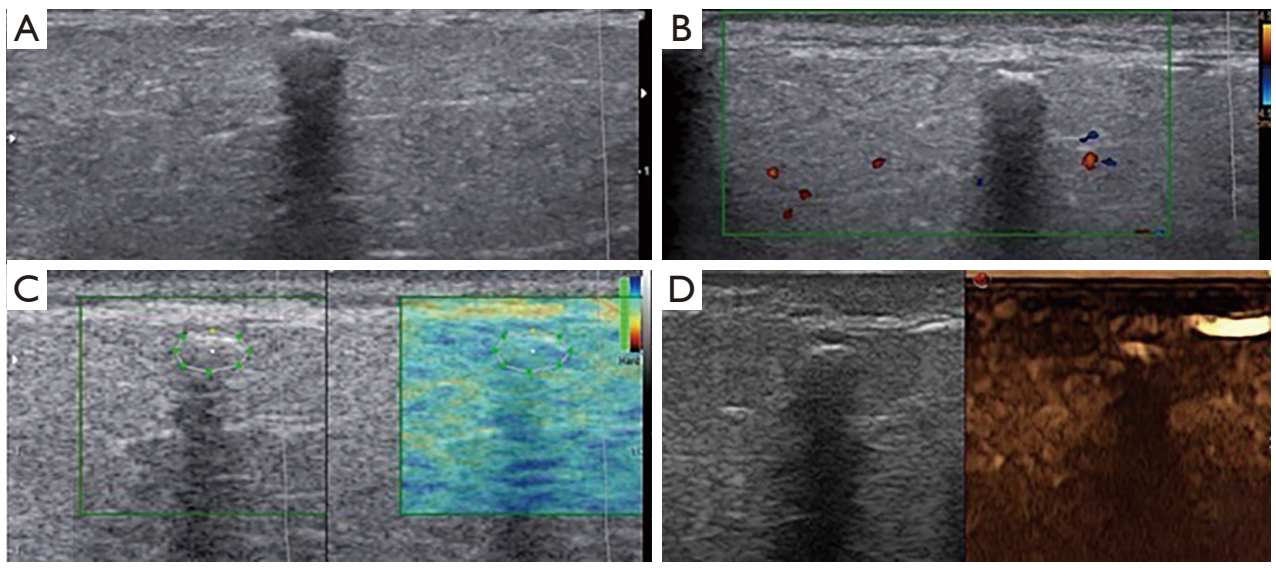

Figure 5 Grey scale (A), color Doppler (B), elastography (C) and CEUS (D) aspect in a patient with sialoadenitis. (A) B-mode US showed a hypoechoic lesion of parotid gland with small calcific formation that causes posterior wall shadowing. The glandular volume appears increased. The presence of one or more calculi is revealed as bright curvilinear echo complex with acoustic shadowing; (B) color-Doppler didn't show vascular signs in the lesion; (C) elastosonography presented a low-intermediate ECI value within the lesion. parotid gland with a calculus demonstrated a reduced tissue elasticity; (D) CEUS didn't show significant enhancement of lesion. It was sialoadenitis. CEUS, contrast-enhanced ultrasound; ECI, elasticity contrast index.
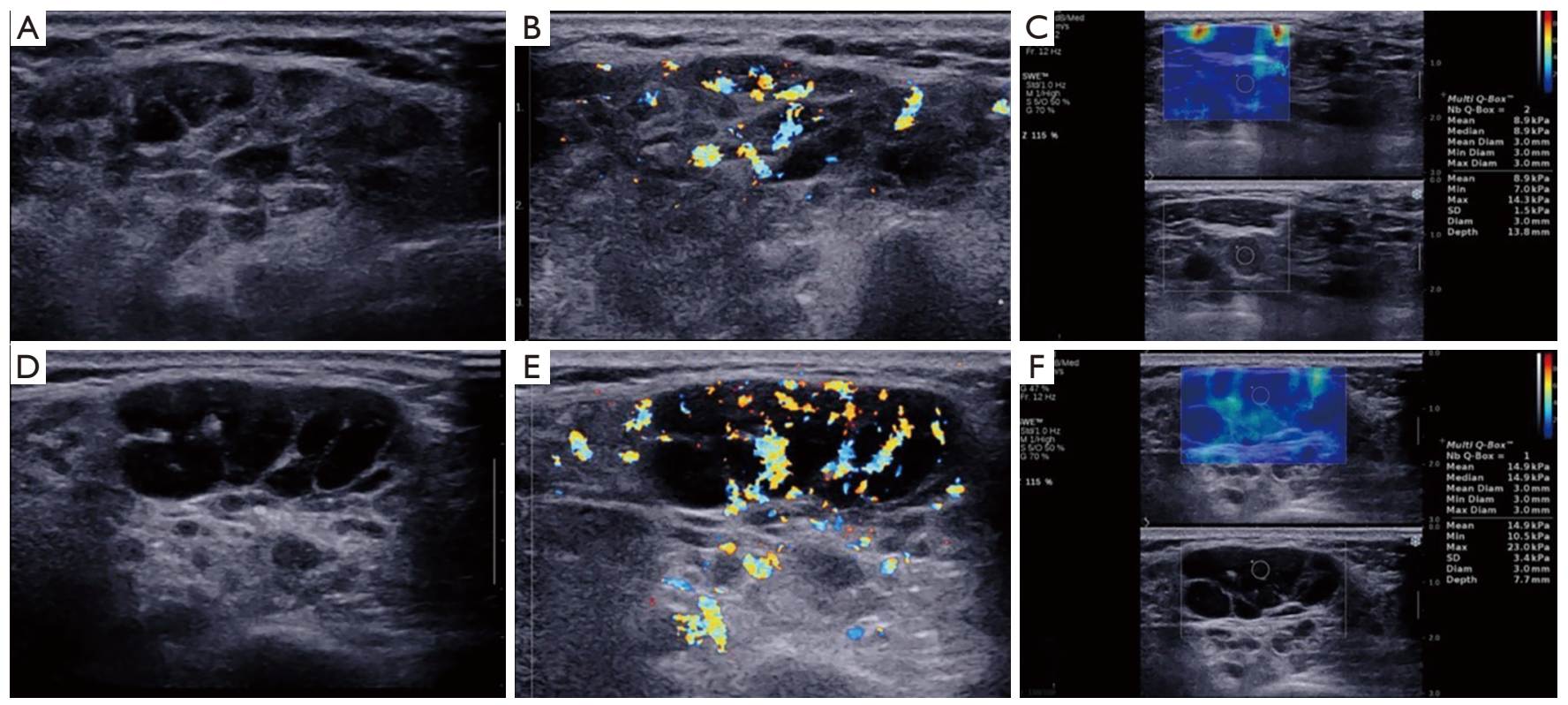

Figure 6 Grey scale (A,D), color Doppler (B,E) and shear wave elastography (C,F) aspect in a patient with typical Sjögren's syndrome (A,B,C) and with lymphoma complication (D,E,F).

healthy subjects (111).

\section{Discussion}

US and CDUS, used routinely to detect parotid lesions are insufficient as predictive markers due to imaging findings overlapping and the moderate vascularization of some benign and malignant tumors, particularly for lowgrade malignancies, as reported in the studies of Knopf et al. (23) and others $(112,113)$. Therefore, the authors 
considered several strategies to improve the reliability of US methods as the realization of a predictive scoring model to assess the major salivary gland tumors (114). Recent studies reported on the use of CD in combination with other techniques avoiding the limit of contrast and ionizing radiation. The study (115) was conducted on 51 parotid gland lesions analysed by non-enhanced MRI and color Doppler flow imaging (CDFI) with valid results for differentiating malignant parotid tumors from benign ones. Other US techniques as CEUS and elastography improve the quality and reliability of the US examination. In several studies $(116,117)$ were reported the value of CEUS to differentiate the different tumor histology on the base of signal changes observed after micro-bubble contrast agent administration. Conversely Badea et al. (118) showed that CEUS alone did not reveal significant differences between benign and malignant circulatory beds of parotid tumors focusing on the necessity of a multimodal approach. The studies conducted on US elastosonographic techniques showed controversial results. Many authors demonstrated differences in elastosonographic scores but they could not prove that they can discriminate between benign and malignant parotid lesions. $(119,120)$. However, elastographic indices showed PA were stiffer than WT, in particular PAs than malignant parotid lesions (120). Indeed, a meta-analysis from 2015 (121) based on the results of nine studies conducted with the use of elastography methods in the differentiation of 581 benign and malignant salivary glands lesions showed good sensitivity and specificity values ( $76 \%$ and $73 \%$, respectively) with malignant lesions commonly harder than benign. Elastography also alone can be used with its high negative predictive value to distinguish benign from malignant lesions as an integrated tool (122). ARFI imaging represents a novel elastography technique resulting a valid method to determine the tissue elasticity of salivary glands in healthy subjects and in several parotid diseases (123). Furthermore, it was postulated that different parotid inflammatory pathologies can be shown by detecting parenchymal changes on elastography. In their study, Zengel et al. (77) demonstrated that ARFI shows promise as a valuable diagnostic tool for assessing disease severity, progression and the treatment response without significantly different values between children and adults in pathological or healthy glands. At the same in the study of Reichel et al. (105) showed the usefulness of ARFI SWV values in parotid glands affected by sialolithiasis. ARFI provided the quantitative evaluation of severity and it is considered useful for monitoring the patient's benefit of therapy regarding tissue. SWE can be also used in the detection of early parenchymal changes even in the HIV patients with homogeneous parotid gland appearance (111). Besides, in the patients with heterogeneous PG appearance, SWE can be used as an assistant for US method. SWE evaluated in few studied, as mentioned, not showed significant difference in parotid gland lesions. Conversely, it is considered a good tool for the assessment of parotid gland diseases such as SS (96). Knopf et al. (124) in 2012 demonstrated the usefulness of SWE and CEUS in SS. Hofauer et al. (125) evaluated different elastographic techniques and concluded that SE could not add any further information compared to B-mode US for the evaluation of salivary gland involvement in SS, but that SWE was the most promising technique. Recently, several authors aimed to show the best performance of US in terms of sensitivity and specificity rates than techniques such as sialography and scintigraphy. In the studies of Milic et al. and Luciano et al. $(126,127)$ is clear the improvement of accuracy for the diagnosis of primary SS (pSS) when US is included in the AECG criteria replacing scintigraphy. US sonographic changes correlate with histological involvement. Color Doppler evaluation however needs further standardization. In SS, for example, the systolic peak velocity after salivary stimulation (with lemon juice) is often double the peak velocity in the resting state. Quantitative SMI values, with their high reproducibility, could become a non-invasive useful technique in diagnosis of pSS (49). Recently, a study was conducted on the added values of GSUS and 2D-SWE of salivary glands performed in 35 patients with pSS. The value of SWE is considered for US pSS diagnosis in cases where the GSUS findings were normal or nonspecific. 2D-SWE of the parotid glands should be considered as a promising imaging technique for detection of parotid lymphoma complication in pSS patients (110). Different authors also showed that SWE was capable to detect changes radiation induced in the elasticity of parotid glands between a radiotherapy group and a reference group $(128,129)$. MPUS has emerged as the first-line imaging modality non-invasive, easily, available for the evaluation of pediatric structural parotid gland. Particularly is considered the absence of radiation exposure $(130,131)$, iodinated contrast material, or sedation and/or anaesthesia. There are also recent studies aimed to establish the index values in healthy children using elastography (SE and SWE) and 
SMI considered the evolution of CD about vascularity. The abnormal stiffness values in children of both sexes in all ages represent an indicator of parotid gland diseases (76). The study of Caliskan et al. (53) comprising a total of 100 subjects determined the reference SWE, SMI, power Doppler, and CD values for normal parotid glands in children and the relationships with sex, age, and body mass index (BMI). Conversely than the previous study mentioned (76) elasticity values correlate with age and BMI. There was no correlation between vascularity values and age, sex, or BMI. SMI provided more detailed information about vascularity compared with the other methods. Another field of interest in connection with salivary gland US is the diagnosis of juvenile SS. US is an effective diagnostic or prognostic tool for different pathologies (132) but it is even frequently applied for invasive procedures $(44,133)$.

In conclusion, baseline US and color Doppler should be integrated by US-elastography and CEUS except when they are able to provide a specific diagnosis as in less common but benign lesions as haemangioma and lipoma. USelastography and CEUS could help to discriminate most of pathologies afflicting parotid gland. However, elastography's role is still under debate with controversial results in different studies concerning the diagnostic performance to distinguish between benign and malignant tumors, but it is effective to discriminate between benign lesions as PA and WT and between WT and malignancies. As demonstrated in our studies and clinical practice (95) PA shows elevated strain ratio suggesting medium/high stiffness and at SWE the colorimetric pattern of the lesion appears "hard" with an E-mean value of about $114.2 \mathrm{kPa}$. Conversely, WT shows low value of strain ratio appearing mainly soft at the elastographic pattern with an E-mean value of $15.1 \mathrm{kPa}$. CEUS showed greater effectiveness to distinguish benign and malignant tumors. with heterogeneous enhancement associated with a suspicious of malignancy, consequently and useful to distinguish PA and WT with the former appearing mostly mildly vascularized and the latter highly and homogeneously enhanced (45).

In clinical practice a multimodal approach, including CEUS and other US imaging techniques, such as USelastography, eventually integrated with MRI, should be suggested to reduce the necessity of FNAC and to guide a proper work-up.

\section{Acknowledgments}

Funding: None.

\section{Footnote}

Provenance and Peer Review: This article was commissioned by the Guest Editor (Antonio Barile) for the series "Multimodality Advanced Imaging and Intervention in Gland Diseases" published in Gland Surgery. The article has undergone external peer review.

Reporting Checklist: The authors have completed the NARRATIVE REVIEW reporting checklist. Available at http://dx.doi.org/10.21037/gs-20-530

Conflicts of Interest: All authors have completed the ICMJE uniform disclosure form (available at http://dx.doi. org/10.21037/gs-20-530). The series "Multimodality Advanced Imaging and Intervention in Gland Diseases" was commissioned by the editorial office without any funding or sponsorship. $\mathrm{AB}$ serves as an unpaid editorial board member of Gland Surgery from Jun 2018 to May 2022 and served as the unpaid Guest Editor of the series. VC reports Lecturer fee from Bracco, Samsung and Toshiba. The other authors have no other conflicts of interest to declare.

Ethical Statement: The authors are accountable for all aspects of the work in ensuring that questions related to the accuracy or integrity of any part of the work are appropriately investigated and resolved.

Open Access Statement: This is an Open Access article distributed in accordance with the Creative Commons Attribution-NonCommercial-NoDerivs 4.0 International License (CC BY-NC-ND 4.0), which permits the noncommercial replication and distribution of the article with the strict proviso that no changes or edits are made and the original work is properly cited (including links to both the formal publication through the relevant DOI and the license). See: https://creativecommons.org/licenses/by-nc-nd/4.0/.

\section{References}

1. Trimboli P, Dietrich CF, David E, et al. Ultrasound and ultrasound-related techniques in endocrine diseases. 
Minerva Endocrinol 2018;43:333-40.

2. .Bartolotta TV, Orlando A, Cantisani V, et al. Focal breast lesion characterization according to the BI-RADS US lexicon: role of a computer-aided decision-making support. Radiol Med 2018;123:498-506.

3. Izzetti R, Fantoni G, Gelli F, et al. Feasibility of intraoral ultrasonography in the diagnosis of oral soft tissue lesions: a preclinical assessment on an ex vivo specimen. Radiol Med 2018;123:135-42.

4. Di Giuliano F, Albanese M, Picchi E, et al. Abnormal cervical lymph nodes in multiple sclerosis: a preliminary ultrasound study. Radiol Med 2018;123:202-8.

5. Gitto S, Grassi G, De Angelis C, et al. A computer-aided diagnosis system for the assessment and characterization of low-to-high suspicion thyroid nodules on ultrasound. Radiol Med 2019;124:118-25.

6. Bruno F, Catalucci A, Arrigoni F, et al. An experiencebased review of HIFU in functional interventional neuroradiology: transcranial MRgFUS thalamotomy for treatment of tremor. Radiol Med 2020;125:877-86.

7. Arrigoni F, Bruno F, Gianneramo C, et al. Evolution of the imaging features of osteoid osteoma treated with RFA or MRgFUS during a long-term follow-up: a pictorial review with clinical correlations. Radiol Med 2020;125:578-84.

8. Ricci P, Cantisani V, Drudi F, et al. Is contrast-enhanced US alternative to spiral CT in the assessment of treatment outcome of radiofrequency ablation in hepatocellular carcinoma? Ultraschall Med 2009;30:252-8.

9. Cantisani V, Ricci P, Erturk M, et al. Detection of Hepatic Metastases From Colorectal Cancer: Prospective Evaluation of Gray Scale US Versus SonoVue® Low Mechanical Index Real Time-Enhanced US as Compared With multidetector-CT or Gd-BOPTA-MRI. Ultraschall Med 2010;31:500-5.

10. Kim DW, Lee YJ, Ahn HS, et al. Comparison of ultrasonography and computed tomography for diagnosing diffuse thyroid disease: a multicenter study. Radiol Med 2018;123:515-23.

11. Kawaguchi M, Kato H, Aoki M, et al. CT and MR imaging findings of infection-free and benign second branchial cleft cysts. Radiol Med 2019;124:199-205.

12. Yildiz, S, Aralasmak, A, Yetis, H, et al. MRI findings and utility of DWI in the evaluation of solid parathyroid lesions. Radiol Med 2019;124:360-7.

13. Aydin S, Fatihoglu E, Kacar M. Intrathyroidal ectopic thymus tissue: a diagnostic challenge. Radiol Med 2019;124:505-9.

14. Ravelli A, Napolitano M, Rustico M, et al. Prenatal MRI of neck masses with special focus on the evaluation of foetal airway. Radiol Med 2019;124:917-25.

15. Tritou I, Raissaki M. Intrathyroidal ectopic thymus tissue: emphasis on details. Radiol Med 2019;124:1064-5.

16. Barile A, Quarchioni S, Bruno F, et al. Interventional radiology of the thyroid gland: critical review and state of the art. Gland Surg 2018;7:132-46.

17. Radzina M, Cantisani V, Rauda M, et al. Update on the role of ultrasound guided radiofrequency ablation for thyroid nodule treatment. Int J Surg 2017;41 Suppl 1:S82-S93.

18. Papini E, Pacella CM, Solbiati LA, et al. Minimallyinvasive treatments for benign thyroid nodules: a Delphibased consensus statement from the Italian minimallyinvasive treatments of the thyroid (MITT) group. Int J Hyperthermia 2019;36:376-82.

19. Barile A, La Marra A, Arrigoni F, et al. Anaesthetics, steroids and platelet-rich plasma (PRP) in ultrasoundguided musculoskeletal procedures. Br J Radiol 2016;89:20150355.

20. Silvestri E, Barile A, Albano D, et al. Interventional therapeutic procedures in the musculoskeletal system: an Italian Survey by the Italian College of Musculoskeletal Radiology. Radiol Med 2018;123:314-21.

21. Mansour N, Bas M, Stock KF, et al. Multimodal Ultrasonographic Pathway of Parotid Gland Lesions. Multimodaler sonografischer Diagnosepfad für Parotisläsionen. Ultraschall Med 2017;38:166-73.

22. Mansour N, Stock KF, Chaker A, et al. Evaluation of parotid gland lesions with standard ultrasound, color duplex sonography, sonoelastography, and acoustic radiation force impulse imaging - a pilot study. Ultraschall Med 2012;33:283-8.

23. Knopf A, Mansour N, Chaker A, et al. Multimodal ultrasonographic characterisation of parotid gland lesions-a pilot study. Eur J Radiol 2012;81:3300-5.

24. Sidhu PS. Multiparametric Ultrasound (MPUS) Imaging: Terminology Describing the Many Aspects of Ultrasonography. Ultraschall Med 2015;36:315-7.

25. Thielker J, Grosheva M, Ihrler S, et al. Contemporary Management of Benign and Malignant Parotid Tumors. Front Surg 2018;5:39.

26. Cantisani V, D'Ambrosio F, Nielsen MB. Multiparametric Ultrasound of Thyroid Nodules: Where Do We Stand? Ultraschall Med 2017;38:357-9.

27. Drudi FM, Cantisani V, Angelini F, et al. Multiparametric MRI Versus Multiparametric US in the Detection of Prostate Cancer. Anticancer Res 2019;39:3101-10. 
28. Drudi FM, Cantisani V, Granata A, et al. Multiparametric ultrasound in the evaluation of kidney disease in elderly. $\mathrm{J}$ Ultrasound 2020;23:115-26.

29. Manetta R, Capretti I, Belleggia N e al. Magnetic resonance enterography (MRE) and ultrasonography (US) in the study of the small bowel in Crohn's disease: state of the art and review of the literature. Acta Biomed 2019;90:38-50.

30. Badarinza M, Serban O, Maghear L, et al. Multimodal ultrasound investigation (grey scale, Doppler and 2D-SWE) of salivary and lacrimal glands in healthy people and patients with diabetes mellitus and/or obesity, with or without sialosis. Med Ultrason 2019;21:257-64.

31. Bialek EJ, Jakubowski W, Zajkowski P, et al. US of the major salivary glands: anatomy and spatial relationships, pathologic conditions, and pitfalls. Radiographics 2006;26:745-63.

32. Kessler AT, Bhatt AA. Review of the Major and Minor Salivary Glands, Part 1: Anatomy, Infectious, and Inflammatory Processes. J Clin Imaging Sci 2018;8:47.

33. Costache A, Dumitru M, Anghel I, et al. Ultrasonographic anatomy of head and neck-a pictorial for the ENT specialist. Med Ultrason 2015;17:104-8.

34. Jousse-Joulin S, Nowak E, Cornec D, et al. Salivary gland ultrasound abnormalities in primary Sjögren's syndrome: consensual US-SG core items definition and reliability. RMD Open 2017;3:e000364

35. Kovacević DO, Fabijanić I. Sonographic diagnosis of parotid gland lesions: correlation with the results of sonographically guided fine-needle aspiration biopsy. J Clin Ultrasound 2010;38:294-8.

36. Sodhi KS, Bartlett M, Prabhu NK. Role of high resolution ultrasound in parotid lesions in children. Int J Pediatr Otorhinolaryngol 2011;75:1353-8.

37. Rzepakowska A, Osuch-Wójcikiewicz E, Maria Sobo M, et al. The differential diagnosis of parotid gland tumors with high-resolution ultrasound in otolaryngological practice. Eur Arch Otorhinolaryngol 2017;274:3231-40.

38. Scotto di Santolo M, Massimo C, Tortora G, et al. Clinical value of high-resolution (5-17 MHz) echo-color Doppler (ECD) for identifying filling materials and assessment of damage or complications in aesthetic medicine/surgery. Radiol Med 2019;124:568-74.

39. Sezer İ, Erdem Toslak İ, Yağci B, et al. The Role of RealTime Tissue Elastography and Gray-Scale Ultrasound Histogram Analysis in the Diagnosis of Patients With Sjögren's Syndrome. Arch Rheumatol 2019;34:371-9.

40. Yang X, Tridandapani S, Beitler JJ. Diagnostic accuracy of ultrasonic histogram features to evaluate radiation toxicity of the parotid glands: a clinical study of xerostomia following head-and-neck cancer radiotherapy. Acad Radiol 2014;21:1304-13.

41. Vidiri A, Minosse S, Piludu F, et al. Cervical lymphadenopathy: can the histogram analysis of apparent diffusion coefficient help to differentiate between lymphoma and squamous cell carcinoma in patients with unknown clinical primary tumor? Radiol Med 2019;124:19-26.

42. Cho HW, Kim J, Choi J, et al. Sonographically guided fine-needle aspiration biopsy of major salivary gland masses: a review of 245 cases. AJR Am J Roentgenol 2011;196:1160-3.

43. Seethala RR, LiVolsi VA, Baloch ZW. Relative accuracy of fine-needle aspiration and frozen section in the diagnosis of lesions of the parotid gland. Head Neck 2005;27:217-23.

44. Oh SH, Seo YK, Kim GT, et al. Power Doppler ultrasound-guided sialography using the phenomenon of increased blood flow: A technical report. Imaging Sci Dent 2019;49:301-6.

45. David E, Cantisani V, De Vincentiis M, et al. Contrastenhanced ultrasound in the evaluation of parotid gland lesions: an update of the literature. Ultrasound 2016;24:104-10.

46. Hata J. Seeing the unseen: new techniques in vascular imaging Superb Microvascular Imaging. Medical Review 2014;10:1-8

47. Cantisani V, David E, Ferrari D, et al. Color Doppler Ultrasound with Superb Microvascular Imaging Compared to Contrast-enhanced Ultrasound and Computed Tomography Angiography to Identify and Classify Endoleaks in Patients Undergoing EVAR. Ann Vasc Surg 2017;40:136-45.

48. Ahn, HS, Lee, JB, Seo, M, et al. Distinguishing benign from malignant thyroid nodules using thyroid ultrasonography: utility of adding superb microvascular imaging and elastography. Radiol Med 2018;123:260-70.

49. Ustabaşığlu FE, Korkmaz S, İlgen U, et al. Quantitative Assessment of Salivary Gland Parenchymal Vascularization Using Power Doppler Ultrasound and Superb Microvascular Imaging: A Potential Tool in the Diagnosis of Sjögren's Syndrome. Balkan Med J 2020;37:203-7.

50. Ohno Y, Fujimoto T, Shibata Y. A new era in diagnostic ultrasound, superb microvascular imaging: preliminary results in pediatric hepato-gastrointestinal disorders. Eur J Pediatr Surg 2017;27:20-5. 
51. Kim HK, O'Hara S, Je BK, et al. Feasibility of superb microvascular imaging to detect high-grade vesicoureteral reflux in children with urinary tract infection. Eur Radiol 2018;28:66-73.

52. Lee YS, Kim MJ, Han SW, et al. Superb microvascular imaging for the detection of parenchymal perfusion in normal and undescended testes in young children. Eur J Radiol 2016;85:649-56.

53. Caliskan E, Ozturk M, Bayramoglu Z. Evaluation of Parotid Glands in Healthy Children and Adolescents Using Shear Wave Elastography and Superb Microvascular Imaging. Radiol Med 2018;123:710-8.

54. Cantisani V, Grazhdani H, Fioravanti C, et al. Liver metastases: Contrast-enhanced ultrasound compared with computed tomography and magnetic resonance. World J Gastroenterol 2014;20:9998-10007.

55. Cantisani V, Bertolotto M, Weskott HP, et al. Growing indications for CEUS: the kidney, testis, lymph nodes, thyroid, prostate, and small bowel. Eur J Radiol 2015;84:1675-84.

56. Sidhu PS, Cantisani V, Dietrich CF, et al. The EFSUMB Guidelines and Recommendations for the Clinical Practice of Contrast-Enhanced Ultrasound (CEUS) in Non-Hepatic Applications: Update 2017 (Long Version). Die EFSUMB-Leitlinien und Empfehlungen für den klinischen Einsatz des kontrastverstärkten Ultraschalls (CEUS) bei nicht-hepatischen Anwendungen: Update 2017 (Langversion). Ultraschall Med 2018;39:e2-e44.

57. Sidhu PS, Cantisani V, Dietrich CF, et al. The EFSUMB Guidelines and Recommendations for the Clinical Practice of Contrast-Enhanced Ultrasound (CEUS) in Non-Hepatic Applications: Update 2017 (Short Version). Die EFSUMB-Leitlinien und Empfehlungen für den klinischen Einsatz des kontrastverstärkten Ultraschalls (CEUS) bei nicht-hepatischen Anwendungen: Update 2017 (Kurzversion). Ultraschall Med 2018;39:154-80.

58. Manetta R, Pistoia ML, Bultrini C, et al. Ultrasound enhanced with sulphur-hexafluoride-filled microbubbles agent (SonoVue) in the follow-up of mild liver and spleen trauma. Radiol Med 2009;114:771-9.

59. Sidhu PS, Cantisani V, Deganello A, et al. Role of Contrast-Enhanced Ultrasound (CEUS) in Paediatric Practice: An EFSUMB Position Statement. Ultraschall Med 2017;38:33-43.

60. Tagliati C, Argalia G, Graziani B, et al. Contrast-enhanced ultrasound in the evaluation of splenic injury healing time and grade. Radiol Med 2019;124:163-9.

61. Tagliati C, Argalia G, Polonara G, et al. Contrast- enhanced ultrasound in delayed splenic vascular injury and active extravasation diagnosis. Radiol Med 2019;124:170-5.

62. Dietrich CF, Averkiou M, Nielsen MB, et al. How to perform Contrast-Enhanced Ultrasound (CEUS). Ultrasound Int Open 2018;4:E2-E15.

63. Wei X, Li Y, Zhang S, et al. Evaluation of microvascularization in focal salivary gland lesions by contrastenhanced ultrasonography (CEUS) and color Doppler sonography. Clin Hemorheol Microcirc 2013;54:259-71.

64. Klotz LV, Gürkov R, Eichhorn ME, et al. Perfusion characteristics of parotid gland tumors evaluated by contrast-enhanced ultrasound. Eur J Radiol 2013;82:2227-32.

65. Klotz LV, Ingrisch M, Eichhorn ME, et al. Monitoring parotid gland tumors with a new perfusion software for contrast-enhanced ultrasound. Clin Hemorheol Microcirc 2014;58:261-9.

66. Sigrist RMS, Liau J, Kaffas AE, et al. Ultrasound Elastography: Review of Techniques and Clinical Applications. Theranostics 2017;7:1303-29.

67. Dietrich CF, Bamber J, Berzigotti A, et al. EFSUMB Guidelines and Recommendations on the Clinical Use of Liver Ultrasound Elastography, Update 2017 (Short Version). Ultraschall Med 2017;38:377-94.

68. Dietrich CF, Bamber J, Berzigotti A, et al. EFSUMB Guidelines and Recommendations on the Clinical Use of Liver Ultrasound Elastography, Update 2017 (Long Version). Ultraschall Med 2017;38:e48.

69. Săftoiu A, Gilja OH, Sidhu PS. The EFSUMB Guidelines and Recommendations for the Clinical Practice of Elastography in Non-Hepatic Applications: Update 2018. Ultraschall Med 2019;40:425-53.

70. Klintworth N, Mantsopoulos K, Zenk J, et al.

Sonoelastography of parotid gland tumours: initial experience and identification of characteristic patterns. Eur Radiol 2012;22:947-56.

71. Ren, X, Xia, S, Ni, Z, et al. Analysis of three ultrasound elastography techniques for grading liver fibrosis in patients with chronic hepatitis B. Radiol Med 2018;123:735-41.

72. Ricci P, Maggini E, Mancuso E, et al. Clinical application of breast elastography: state of the art. Eur J Radiol 2014;83:429-37.

73. Cantisani V, David E, Grazhdani H. Prospective Evaluation of Semiquantitative Strain Ratio and Quantitative 2D Ultrasound Shear Wave Elastography 
(SWE) in Association with TIRADS Classification for Thyroid Nodule Characterization. Ultraschall Med 2019;40:495-503.

74. Mulazzani L, Cantisani V, Piscaglia F. Different techniques for ultrasound liver elastography. J Hepatol 2019;70:545-7.

75. Cantisani V, David E, De Virgilio A, et al. Prospective evaluation of Quasistatic Ultrasound Elastography (USE) compared with Baseline US for parotid gland lesions: preliminary results of elasticity contrast index (ECI) evaluation. Med Ultrason 2017;19:32-8.

76. Gungor G, Yurttutan N, Bilal N, et al. Evaluation of parotid glands with real-time ultrasound elastography in children. J Ultrasound Med 2016;35:611-5.

77. Zengel P, Reichel CA, Vincek T, et al. Ultrasound elastography in diagnosis and follow-up for patients with chronic recurrent parotitis. Clin Hemorheol Microcirc 2017;67:389-97.

78. Lobo R, Hawk J, Srinivasan A. A Review of Salivary Gland Malignancies: Common Histologic Types, Anatomic Considerations, and Imaging Strategies. Neuroimaging Clin N Am 2018;28:171-82.

79. Kuan EC, Mallen-St Clair J, St John MA. Evaluation of Parotid Lesions. Otolaryngol Clin North Am 2016;49:313-25.

80. Riccardi L, De Monte F, Cretti F, et al. Use of radiation dose index monitoring software in a multicenter environment for CT dose optimization. Radiol Med 2018;123:944-51.

81. Paolicchi F, Bastiani L, Guido D, et al. Radiation dose exposure in patients affected by lymphoma undergoing repeat CT examinations: how to manage the radiation dose variability. Radiol Med 2018;123:191-201.

82. Nardi C, Salerno S, Molteni R, et al. Radiation dose in non-dental cone beam CT applications: a systematic review. Radiol Med 2018;123:765-77.

83. Patel A, Jackson B. Low-dose radiation use in diagnostic imaging and cancer therapy settings. Radiol Med 2018;123:618-9.

84. Agostini A, Borgheresi A, Mari A, et al. Dual-energy CT: theoretical principles and clinical applications. Radiol Med 2019;124:1281-95.

85. Tomà $\mathrm{P}$, Bartoloni $\mathrm{A}$, Salerno $\mathrm{S}$, et al. Protecting sensitive patient groups from imaging using ionizing radiation: effects during pregnancy, in fetal life and childhood. Radiol Med 2019;124:736-44.

86. Agostini A, Mari A, Lanza C, et al. Trends in radiation dose and image quality for pediatric patients with a multidetector CT and a third-generation dual-source dual- energy CT. Radiol Med 2019;124:745-52.

87. Cicero G, D'angelo T, Racchiusa S, et al. Cross-sectional Imaging of Parotid Gland Nodules: A Brief Practical Guide. J Clin Imaging Sci 2018;8:14.

88. Vogl TJ, Albrecht MH, Nour-Eldin NA, et al. Assessment of salivary gland tumors using MRI and CT: impact of experience on diagnostic accuracy. Radiol Med 2018;123:105-16.

89. Masciocchi C, Fascetti E, Cutilli T, et al. Role of magnetic resonance in the radiologic diagnosis of parotid pathology. Radiol Med 1988;75:626-31.

90. Petralia G, Padhani AR, Pricolo P, et al. Wholebody magnetic resonance imaging (WB-MRI) in oncology: recommendations and key uses. Radiol Med 2019;124:218-33.

91. Splendiani A, Perri M, Marsecano C, et al. Effects of serial macrocyclic-based contrast materials gadoterate meglumine and gadobutrol administrations on gadoliniumrelated dentate nuclei signal increases in unenhanced T1weighted brain: a retrospective study in 158 multiple sclerosis (MS) patients. Radiol Med 2018;123:125-34.

92. Pasquini L, Rossi Espagnet MC, Napolitano A, et al. Dentate nucleus T1 hyperintensity: is it always gadolinium all that glitters? Radiol Med 2018;123:469-73.

93. Salerno S, Granata C, Trapenese M, et al. Is MRI imaging in pediatric age totally safe? A critical reprisal. Radiol Med 2018;123:695-702.

94. Rubini A, Guiban O, Cantisani V, et al. Multiparametric ultrasound evaluation of parotid gland tumors: B-mode and color Doppler in comparison and in combination with contrast-enhanced ultrasound and elastography. A case report of a misleading diagnosis. J Ultrasound 2020. [Epub ahead of print]. doi: 10.1007/s40477-020-00469-4.

95. Cantisani V, David E, Sidhu PS. Parotid Gland Lesions: Multiparametric Ultrasound and MRI Features. Ultraschall Med 2016;37:454-71.

96. Mansour N, Hofauer B, Knopf A. Ultrasound Elastography in Diffuse and Focal Parotid Gland Lesions. ORL J Otorhinolaryngol Relat Spec 2017;79:54-64.

97. Diouf MS, Claros P, Claros A. Oncocytoma of the parotid gland: a case report. Rev Laryngol Otol Rhinol (Bord) 2012;133:109-12.

98. Higashino M, Kawata R, Haginomori S, et al. Novel differential diagnostic method for superficial/deep tumor of the parotid gland using ultrasonography. Head Neck 2013;35:1153-7.

99. Tomà $\mathrm{P}$, Esposito F, Granata C, et al. Up-to-date imaging review of paediatric soft tissue vascular masses, focusing on 
sonography. Radiol Med 2019;124:935-45.

100.Katz P, Hartl DM, Guerre A. Clinical ultrasound of the salivary glands. Otolaryngol Clin North Am 2009;42:973-1000.

101. Inarejos Clemente EJ, Navallas M, Tolend M, et al. Imaging Evaluation of Pediatric Parotid Gland Abnormalities. Radiographics 2018;38:1552-75.

102. Mandalia UY, Porte FN, Howlett DC. Salivary Gland: Oncologic Imaging. Ultrasound Clin 2014;9:99-113.

103. Bansal AG, Oudsema R, Masseaux JA. US of Pediatric Superficial Masses of the Head and Neck. Radiographics 2018;38:1239-63.

104.Zajkowski P, Ochal-Choińska A. Standards for the assessment of salivary glands - an update. J Ultrason 2016;16:175-90.

105. Reichel CA, Vincek T, Gellrich D, et al. Ultrasound elastography in diagnosis and follow-up for patients with sialolithiasis. Dentomaxillofac Radiol 2018;47:20170424.

106. Shiboski CH, Shiboski SC, Seror R, et al. 2016 American College of Rheumatology/ European League against rheumatism classification criteria for primary Sjögren's syndrome: a consensus and data-driven methodology involving three international patient cohorts. Ann Rheum Dis 2017;76:9-16.

107.Jousse-Joulin S, D'Agostino MA, Nicolas C, et al. Video clip assessment of a salivary gland ultrasound scoring system in Sjögren's syndrome using consensual definitions: an OMERACT ultrasound working group reliability exercise. Ann Rheum Dis 2019:78:967-73.

108. Wierzbicka M, Kaluzny J, Ruchala M, et al. Sonoelastography-a useful adjunct for parotid gland ultrasound assessment in patients suffering from chronic inflammation. Med Sci Monit 2014;20:2311-7.

109. Arslan S, Durmaz MS, Erdogan H, et al. Two-dimensional shear wave elastography in the assessment of salivary gland involvement in primary Sjögren's. J Ultrasound Med 2020;39:949-56.

110. Bădărînză M, Serban O, Maghear L, et al. Shear wave elastography as a new method to identify parotid lymphoma in primary Sjögren Syndrome patients: an observational study. Rheumatol Int 2020;40:1275-81.

111. Kara M, Caliskan E, Atay G, et al. Shear wave elastography of parotid glands in pediatric patients with HIV infection. Radiol Med 2019;124:126-31.

112. Bradley MJ, Durham LH, Lancer JM. The role of colour flow Doppler in the investigation of the salivary gland tumour. Clin Radiol 2000;55:759-62.

113. Schick S, Steiner E, Gahleitner A, et al. Differentiation of benign and malignant tumors of the parotid gland: value of pulsed Doppler and color Doppler sonography. Eur Radiol 1998;8:1462-7.

114.Lo WC, Chang CM, Wang CT, et al. A Novel Sonographic Scoring Model in the Prediction of Major Salivary Gland Tumors. Laryngoscope 2021;131:E157-62.

115.Zhang W, Zuo Z, Luo N, et al. Non-enhanced MRI in combination with color Doppler flow imaging for improving diagnostic accuracy of parotid gland lesions. Eur Arch Otorhinolaryngol 2018;275:987-95.

116. Steinhart H, Zenk J, Sprang K, et al. Contrast-enhanced color Doppler sonography of parotid gland tumors. Eur Arch Otorhinolaryngol 2003;260:344-8.

117. Fischer T, Paschen CF, Slowinski T, et al. Differentiation of parotid gland tumors with contrast-enhanced ultrasound. Rofo 2010;182:155-62.

118. Badea AF, Bran S, Tamas-Szora A, et al. Solid parotid tumors: an individual and integrative analysis of various ultrasonographic criteria. A prospective and observational study. Med Ultrason 2013;15:289-98.

119. Dumitriu D, Dudea SM, Botar-Jid C, et al. Ultrasonographic and sonoelastographic features of pleomorphic adenomas of the salivary glands. Med Ultrason 2010;12:175-83.

120. Bhatia KS, Cho CC, Tong CS, et al. Shear wave elastography of focal salivary gland lesions: preliminary experience in a routine head and neck US clinic. Eur Radiol 2012;22:957-65.

121. Liu Y, Li J, Tan YR, et al. Accuracy of diagnosis of salivary gland tumors with the use of ultrasonography, computed tomography, and magnetic resonance imaging: a metaanalysis. Oral Surg Oral Med Oral Pathol Oral Radiol 2015;119:238-245.e2.

122.Karaman CZ, Başak S, Polat YD, et al. The Role of Real-Time Elastography in the Differential Diagnosis of Salivary Gland Tumors. J Ultrasound Med 2019;38:1677-83.

123.Zengel P, Schrötzlmair F, Schwarz F, et al. Elastography: a new diagnostic tool for evaluation of obstructive diseases of the salivary glands; primary results. Clin Hemorheol Microcirc 2012;50:91-9.

124.Knopf A, Hofauer B, Thürmel K, et al. Diagnostic utility of Acoustic Radiation Force Impulse (ARFI) imaging in primary Sjoegren`s syndrome. Eur Radiol 2015;25:3027-34.

125. Hofauer B, Mansour N, Heiser C, et al. Sonoelastographic Modalities in the Evaluation of Salivary Gland Characteristics in Sjögren's Syndrome. Ultrasound Med 
Biol 2016;42:2130-9.

126. Milic V, Petrovic R, Boricic I, et al. Ultrasonography of major salivary glands could be an alternative tool to sialoscintigraphy in the American-European classification criteria for primary Sjogren's syndrome. Rheumatology (Oxford) 2012;51:1081-5.

127.Luciano N, Baldini C, Tarantini G. Ultrasonography of major salivary glands: a highly specific tool for distinguishing primary Sjögren's syndrome from undifferentiated connective tissue diseases. Rheumatology (Oxford) 2015;54:2198-204.

128. Badea I, Tamas-Szora A, Chiorean I, et al. Acoustic Radiation Force Impulse quantitative elastography: a new noninvasive technique for the evaluation of parotid glands. A preliminary study in controls and in patients with irradiated nasopharyngeal carcinoma. Med Ultrason 2015;17:308-14.

129. Kałużny J, Kopeć T, Szczepanek-Parulska E, et al. Shear

Cite this article as: Martino M, Fodor D, Fresilli D, Guiban O, Rubini A, Cassoni A, Ralli M, De Vincentiis C, Arduini F, Celletti I, Pacini P, Polti G, Polito E, Greco A, Valentini V, Sorrenti S, D'Andrea V, Masciocchi C, Barile A, Cantisani V. Narrative review of multiparametric ultrasound in parotid gland evaluation. Gland Surg 2020;9(6):2295-2311. doi: 10.21037/gs-20530 wave elastography: a new noninvasive tool to assess the intensity of fibrosis of irradiated salivary glands in head and neck cancer patients. Biomed Res Int 2014;2014:157809.

130. Nardone V, Tini P, Nioche C, et al. Texture analysis as a predictor of radiation-induced xerostomia in head and neck patients undergoing IMRT. Radiol Med 2018;123:415-23.

131.Kim DW. Computed tomography features of the major salivary glands after radioactive iodine ablation in patients with papillary thyroid carcinoma. Radiol Med 2018;123:20-7.

132. Nieto-González JC, Monteagudo I, Bello N, et al. Salivary gland ultrasound in children: a useful tool in the diagnosis of juvenile Sjögren's syndrome. Clin Exp Rheumatol 2014;32:578-80.

133. Scattergood S, Moore S, Prior A, et al. Percutaneous drainage of a parotid gland abscess under contrastenhanced ultrasound guidance: A case report. Ultrasound 2018;26:182-6. 